\title{
Monitoring and Evaluation Systems and Performance of Non-Governmental Based Maternal Health Projects in Bungoma South Sub-County, Kenya
}

\author{
Nalianya Japheth Micah \\ Dr. Stephen Wanyonyi Luketero \\ University of Nairobi, Nairobi, Kenya
}

doi: 10.19044/esj.2017.v13n23p11 URL:http://dx.doi.org/10.19044/esj.2017.v13n23p11

\section{Abstract}

The growth in number and size of non-governmental organizations in Kenya has been met with a growing concern about identifying their achievements and effectiveness of their projects. The struggle by majority of NGOs account for their work and demonstrate real results continues to taint their image as development change agents to various stakeholders. One way organizations can improve effectiveness of their interventions is by strengthening their monitoring and evaluation systems. This study sought to determine the influence of monitoring and evaluation systems on performance of non-governmental based maternal health projects in Bungoma South Sub-County, Kenya. Specific objectives were to: determine how monitoring and evaluation plans, human Resource capacity, nature of monitoring and evaluation information systems adopted, and stakeholder participation in monitoring and evaluation influence performance of nongovernmental maternal health projects in Bungoma South Sub-County. A descriptive survey design and correlation design was employed. With a target population of 101 respondents, a census was conducted on all respondents involved in implementation of maternal health projects from the three non-governmental organizations (AA, STC, and CREADIS). Data was collected through questionnaires and analyzed using descriptive statistics. A fairly strong correlation of $0.607,0.530,0.533$ and -0.489 for monitoring and evaluation plans, human resource capacity, nature of information system adopted, and stakeholder participation respectively and performance of maternal health projects. The regression analysis indicated that, taking all the independent variables at a constant zero, performance of maternal health projects was 4.087. The study recommends alignment of staff job descriptions with their $M \& E$ plans, increase the number of $M \& E$ training, conduct Routine Data Quality Assessment to detect areas of difficulties to staff, invest in Information and Communication Technology, and manage 
stakeholders' involvement in Monitoring and Evaluation in order to achieve quality data.

Keywords: M\&E plans, human resource capacity, M\&E information systems, stakeholder participation, Performance

\section{Introduction}

\section{Background of the Study}

In their course of complementing government efforts in improving the lives of its citizen, non-governmental Organizations (NGOs) around the world have initiated and implemented projects in various sectors such as agriculture, health, human rights and community empowerment. To a large extend, the success of such projects has always depended on the monitoring and evaluation of the projects. The World Health Organization (2006) observes that monitoring progress to our goals and evaluating the impact of our interventions and actions are essential to improving performance and achieving results. Prabhakar, (2008) also points out that monitoring and feedback is one of factors leading to project success. However, the effectiveness of work of NGOs has not been felt by the targeted beneficiaries, globally. In the field of maternal health, the proportion of mothers that do not survive childbirth compared to those who do-in developing regions is still 14 times higher than in developed regions (United Nations, 2015). Further, it is estimated that about 830 women die from pregnancy- or childbirth-related complications around the world everyday (WHO,2016). This situation points to the inadequate and ineffective programmes and projects aimed at addressing societal challenges despite efforts from both the government and NGOs.

Concerns about performance and effectiveness of projects in NGOs have emerged. Kareithi \& Lund (2012) observe that since the 1990s, the role of development NGOs in international development has increased, along with massive interest and concern over NGO performance from NGO practitioners, governments, citizens, donors, policymakers and academics. Calls for effectiveness and sustainability of NGOs projects has consequently placed pressures on NGOs to undertake increased monitoring and evaluation and present measurable indicators of output, impact and capacity (AHMED, 2004). A look at M\&E systems in government and NGOs around the world reveal weaknesses in the systems that curtail achievement of project results. In Canada, accountability is a highly-held norm in government and charity organizations. However, emphasis is largely placed on financial accountability. (Kirsch, 2013) observes that although financial accountability has been around for thousands of years in Canada...fairness and performance accountability standards have not been developed at the country or 
international levels but rather at the discretion of individual practitioners, organizational directives or rules established by funders. In addition, monitoring for results seem not to be prioritized with emphasis being placed on implementation monitoring of projects in charity organizations. (Kirsch, 2013) observes that much of the performance accountability by charities in Canada has been about inputs and outputs without regard to outcomes and impacts, or the resulting value to the community. This is the reason that funding organizations such as Canadian International Development Agency (CIDA) are applying pressure on charities to demonstrate results or lose funding (Wyld, 2012).

Accountability among NGOs in Bangladesh has been described as "perfunctory" by (AHMED, 2004). This is evident with the challenges noted in $\mathrm{M} \& \mathrm{E}$ systems especially in maternal health, research and development projects implemented by both the government (within the Ministry of Health and Family Welfare), and NGOs (Rahman, Parkhurst, \& Normand, 2003). Community health workers with little experience and skills in M\&E are responsible for delivering essential service packages, are in charge of monitoring and surveillance i.e. collecting data on maternal and infant deaths, pregnancies, births and incidence and prevalence of certain communicable diseases (WHO, 2006).Such inadequate M\&E skills implies therefore that the quality of data generated by the $M \& E$ is unreliable and which might be misleading to the project as a whole.

In Botswana, where biomedical evidence between HIV/AIDS and maternal mortality suggests the linkages are strong (WHO, 2014), concerns have emerged about monitoring and evaluation of HIV/AIDS and MHPs. M\&E practices in NGOs implementing HIV/AIDS projects in Gaborone city are weak and fall below the best practices where most of the best practices were inconsistently done and others were not done at all (Muzinda, 2007). Further, HIV/AIDS project failures have also been attributed to limited stakeholder participation in M\&E where exclusion of local leaders, ethnic groups and communities in the creation of national HIV prevention campaigns which led to the development of untrustworthy and ineffective campaigns (SU, 2010).

Although the scope of NGOs in Ethiopia is still small and confined mostly to Addis Ababa (Clark, 2000), the ineffectiveness of their work has also been observed owing to inability by NGOs to demonstrate and achieve project results, despite the huge resources at their disposal. Studies on functioning of local NGOs project implementation, monitoring and evaluation show that short term project objectives of local NGOs have been achieved with positive, but often scattered little results. Yet, many studies say little beyond the more immediate effects of the projects, particularly they 
did not address monitoring and evaluation practices and challenges of local NGOs executing education projects in Addis Ababa (Tulema, 2014).

Challenges in implementation and monitoring and evaluation of maternal health and other related programmes in Kenya explains the ineffectiveness of these programmes. An assessment of M\&E functions at the Division of Reproductive Health by Ministry of Health in Kenya revealed the weakest areas to be; supervision and auditing processes, human capacity for $\mathrm{M} \& \mathrm{E}$ functions, Research and Surveillance, and development of national and sub-national databases (MOH-Kenya, 2013). The M\&E dimensions such as status, quality, technical autonomy, and financial autonomy all received below average ratings pointing to the weak organizational capacity of DRH's mandate to carry out its M\&E mandate (MOH-Kenya, 2013). Therefore, critical assessment of composition of M\&E systems in government and NGOs in Kenyais key in identifying areas of weakness strengthening the system to be more reliable in managing projects.

\section{Statement of the problem}

With more than 8500 NGOs (National Council of NGOs Kenya, 2014) operating in Kenya since the 1990s, questions about their significance have emerged. Ooko,(2014) in her article, NGOs and Development in Africa: Lessons for Donors, poses the following questions: With so many NGOs in Kenya, why such little progress? How comes whenever NGOs begin work in an area, livelihoods seem to improve, but once they close shop, the gains made are often reversed and communities continue to suffer?These questions points to weaknesses in programmatic approach amongst NGOs in solving societal challenges such as high maternal health deaths especially in developing countries.Kirsch (2013) notes that effectiveness is becoming a concern of the global development community. There are calls on NGOs to focus on and show real results. Davies (2001) points out that, associated with the growth (of NGOs) has been a growing concern about identifying the achievements of NGOs. However, there is little response from NGOs to the growing demand for public accountability to citizens on how assistance is used, what results are achieved, and how appropriate these results are, in bringing about desired changes in human development. (Karani, Bichanga, \& Kamau, 2014) caution that, if you can't measure how well you are doing against targets and indicators, you may go on using resources, without changing the circumstances you have recognized as a problem at all. In addition, there has been an increase in negative unintended consequences from NGOs projects/programmes. For example, researchers have found residents in communities around Lake Victoria using mosquito nets for fishing and drying fish instead of using them in their homes to combat 
malaria as intended (Minakawa, Dida, Sonye, Futami, \& Kaneko, 2008) as cited by (Were,2014).

Accounts of development projects gone wrong, the increasing influence NGOs play in development, and historically poor assessment practices among NGOs all raise questions about how NGO project administrators understand impacts of their activities (Were, 2014). Despite M\&E being a critical factor in the project success, it is one area of weakness for many projects and programmes (UNDP, 2009) among NGOs. Program and project managers pay little attention to $M \& E$, viewing it as a burden that should be avoided. Many at times M\&E is given a much lower priority at the project's inception, as all efforts are aimed at launching the project (Lahey, 2015). This arises, partly, due to the limited resources available even for project start-up and delivery, with often limited follow-through on implementation of the performance measurement strategies and M\&E Plan, in spite of how well defined they may be (Lahey, 2015). For most NGO's, $M \& E$ is perceived as extra work and therefore in the rush of implementation, they leave out monitoring (tracking progress) themselves to be done by one individual (M\&E Officer) with little support from other staff or management (Emmanuel, 2015). This makes it difficult to know if accomplishments could be achieved sooner, at a significantly reduced overall expenditure, by learning from successes and failures and applying the lessons to new interventions (Kirsch, 2013).

Therefore, the study sought to study the M\&E systems among NGOs implementing MHPs in Bungoma South-Sub County and how such systems influence performance of the projects. In this case, an M\&E system refers to a collection of people, procedures, data and technology that interact to provide timely information for authorized decision-makers. Particular focus was placed on M\&E planning, human resource capacities, stakeholder participation and information systems employed in $\mathrm{M} \& \mathrm{E}$.

\section{Objectives of the study}

The objectives of the study were to:

i.Determine how monitoring and evaluation plans influence performance of non-governmental based maternal health projects in Bungoma South SubCounty

ii.Determine how human Resource capacity for monitoring and evaluation influence performance of non-governmental based maternal health projects in Bungoma South Sub-County.

iii.Determine the extent to which nature of monitoring and evaluation information systems adopted influence performance of non-governmental based maternal health projects in Bungoma South Sub-County. 
iv.Examine how stakeholder participation in monitoring and evaluation influence performance of non-governmental based maternal health projects in Bungoma South Sub-County.

\section{Literature review}

\section{Performance of Non-Governmental Based Projects}

NGOs around the world have struggled with the question of accountability of their work. This is as a result of different informational demands that their work attracts from various stakeholders. Lewis \& Kanji, (2009) observe that accountability is a complex challenge for NGOs, because they have multiple constituencies and need to be accountable in different ways to a variety of different groups and interests. Ramadan \& Borgonovi (2015) approves this view noting that NGOs are required to manage and evaluate their performance from multiple perspectives, taking into account the projects/programs performance, the agenda of donors, the needs of beneficiaries and the internal effectiveness. It is a situation that has raised concern on performance of NGO projects from various stakeholders. Kareithi \& Lund (2012) observe that the role of development NGOs in international development has increased, along with massive interest and concern over NGO performance from NGO practitioners, governments, citizens, donors, policymakers and academics. This is because there is still a lack of reliable evidence on the impact of NGO development projects and programmes (Davies, 2001). The term "performance" connotes a set of results that represent productivity, progress and competence related to an established objective, goal, or standards of accuracy, completeness, cost, quality and speed. According to Carman (2007), the most utilized performance indicators by NGOs incorporate efficiency, effectiveness, fundraising, costs, audits and beneficiaries' satisfaction. That means measuring performance of projects/programmes will involveassessing the method that evaluates efficiency and effectiveness of a project/program and its impact (Miller, 2007) as cited by (Ramadan \& Borgonovi, 2015). Therefore, there is need to establish and strengthen a project performance $\mathrm{M} \& \mathrm{E}$ which is critical component in a well-functioning project as it ensures performance-based result (IFAD, 2010).

\section{Nature of Monitoring and Evaluation Planning and Performance of Non-Governmental Based Projects}

M\&E planning is an essential component of the $M \& E$ system, involving a practical planning for the project/programme to monitor and evaluate the log frame's objectives and indicators (IFRC, 2011). M\&E plan assists in managing the process of assessing and reporting progress towards achieving project outputs and outcomes, and to identify what evaluation 
questions will be addressed through evaluation (USAID, 2016). Specifically, the $\mathrm{M} \& \mathrm{E}$ plan describes indicators, who is responsible for collecting them, what forms and tools will be used, and how the data will flow through the organization (Bullen, 2014). This means, without M\&E plans, many M\&E systems will fall into disuse because too little attention is given to detail at the planning stage (Sinister, 2015).

M\&E plans should be documented during and shared between all stakeholders including the donors. This is the best practice which suggests as wide an engagement with different stakeholders as possible, and certainly anyone expected to carry out the work contained in the plan should be informed or consulted during its development (Simister, 2015). However, studies done on involvement of stakeholders in M\&E plans have been limited to identifying the level involvement, without touching on its influence in project performance. Githika (2013) in his study involving of stakeholders in M\&E of HIV projects of civil society organizations (CSOs) in Imenti North Sub County, the study concluded that the CSOs in HIV projects were yet to embrace participatory monitoring and evaluation. Using the descriptive research design, the study established that involvement of donors, staff, community, and project beneficiaries M\&E planning of projects stood at $16.1 \%, 48.4 \%, 11.3 \%$ and $24.2 \%$ respectively. However, questions on the importance of stakeholder involvement, their specific roles and inputs, and implications of their limited involvement in M\&E planning remain unexplored. SFCG(2010) observes that M\&E plan allows all staff involved with the project to have a reference sheet of all the M\&E activities during the progress of the project and highlights data. USAID (2007) adds that developing the (M\&E) system in a participatory manner ensures that groups involved in collection and analysis of the information will understand what they are collecting and why it is important. This also enables the M\&E planners to allocate time and resources for the various M\&E activities and alert them to the time and resources required for proper M\&E work (Taylor, 2001).

$M \& E$ plans should be revised, reviewed and updated with time based on the changing environment or situations in regard to implementation of a programme. This ensures that the $M \& E$ plan remain relevant in guiding implementation of a programme. According to (SFCG, 2010), M\&E plan should be constantly updated to include up-to-date information of monitoring and evaluation progress. But how important frequent and important it is to update an M\&E plan? Simister (2015) points out that changes might need to be made because $M \& E$ systems or processes are not working properly, or because the project or programme itself has changed, and the M\&E approach needs to be altered as a result. Further UNDP(2009) points out that M\&E activities take place throughout the programme and project cycles and should 
be reviewed and updated regularly (at least annually, for example at the time of annual reviews). This ensures that the project is always responding to the problems identified in the community despite the changing circumstances.

The scope of M\&E plans differs depending on the size of a programme and the size of the organization. An M\&E plan with a narrower scope, also known as an indicator matrix or an M\&E framework, is a specific document that defines project indicators and how they will be measured (Chaplowe, 2008) ensuring that firm plans are in place to collect the indicators defined in a project or programme plan. Some of the common features in the indicator matrices include: the relevant output or objective; the indicator; the source of information used to collect the indicator; the person responsible for collection; when the indicator should be collected and the frequency of data collection on the indicator. The other type of $\mathrm{M} \& \mathrm{E}$ plan encompasses the broader aspects of $\mathrm{M} \& \mathrm{E}$, incorporating the indicator matrix in addition to issues involving the analysis and use of information, reporting schedules, learning mechanisms, training, knowledge management and resources (Simister,2015). Studies done on scope of M\&E plans have tended lean towards the narrower scope of M\&E plans which is essential during implementation of M\&E activities. A study by Bernard Phiri (2015) for instance, analyzed the influence of the scope M\&E plans on performance of two projects (the Multinational Project (MNP) and the Virtual University for Cancer Control Network (VUCCnet)) successfully implemented by Afrcian Virtual University (AVU). The study found that AVU had an M\&E plan of a narrow scope consisting of Objectives of the project (23) Determination of project performance (21), project indicators (19); outputs and outcomes (19), conceptual measures and definitions, along with baseline data and a Monitoring schedule. This means that consideration was given to achievement of project outputs, outcomes and goals... and that the M\&E plan's role was to guide the tracking of achievement of results and provide information on what is happening in the project through data collection (Phiri, 2015). Aspects of the broader M\&E plans such as analysis and use of information, data management and reporting schedules, learning mechanisms, training, knowledge management and resources were not explored.

\section{Human Resource Capacity in Monitoring and Evaluation and Performance of Non-Governmental Based Projects}

Capacity can be understood as the ability of people, organizations and society as a whole to manage their affairs successfully (OECD, 2006). M\&E activities utilizes the capacities of many people such as staff, beneficiaries and volunteers who are not M\&E experts (Chaplowe, 2008). It is critical that capacity building and development of various people involved 
in $\mathrm{M} \& \mathrm{E}$ is planned and carried out on a regular basis for successful implementation of M\&E work. As noted by UNDP (2009), there is the need to take a more holistic view in identifying and addressing the capacities needed to monitor and evaluate the results being pursued. According to (Acevedo, Rivera, Lima, \& Hwang, 2010) building an adequate supply of human resource capacity is critical for the sustainability of the M\&E system.

UNDP (2009) observes that staff entrusted with monitoring should have required technical expertise in the area. Among Donor funded projects in NGOs, Nyakundi (2014) found out that staff technical skills affect the implementation of $\mathrm{M} \& \mathrm{E}$, in that necessary skills play a key role in providing functional advice in the development of appropriate results-based performance monitoring systems. In quantitative terms, Nyakundi (2014) showed that a unit increase in technical skills would lead to 0.122 efficiency in the implementation of $\mathrm{M} \& \mathrm{E}$. It means therefore that with competent M\&E skills, projects are able to achieve their planned results. This result agrees with findingins by Ngatia (2015) which showed that a unit increase in human resource would lead to 0.288 increase in performance of agribusiness projects in NGOs in Murang'a County. However, even with high demand for expertise in $\mathrm{M} \& \mathrm{E}$, and with the increasing focus of donors and borrowers on impact (Rajalahti, Woelcke, \& Pehu, 2005), scorlars have found inadequate expertise in M\&E both in government and NGOs staff with M\&E roles. There are simply too few people in most Sub-Saharan African countries with the necessary skills and capacity of designing and implementing M\&E activities... as such many NGOs lack the technical expertise, knowledge and understanding of M\&E (Emmanuel, 2015). Among NGOs implementing HIV/AIDS projects in Botswana, Muzinda (2007) found that implementing the monitoring and evaluation process was not effectively done due to, among other reasons, inadequate finances, lack of expertise, stringent and multi-donor reporting requirements. Although the study by Muzinda didn't elaborate on performance of the NGOs HIV projects in the country, the study showed that all the projects implemented by the local NGOs in Botswana were not effectively monitored and evaluated (Muzinda,2007). In government infrastructural projects in Kenya, study by Wanjiku (2015) noted inadequate training and $M \& E$ expertise observing the absence of $M \& E$ expertise such as design skills particularly Log Frame design, indicator setting, design of data collection instruments, with non-existent with data collection skills.

Apart from technical know-how, staff with M\&E working experience ensure effective implementation of their interventions. In assessing and planning for human resource capacity, the first step is to determine the available $M \& E$ experience within the project/programme team, partner organizations, target communities and any other potential participants in the 
M\&E system (IFRC, 2011). This is because effective M\&E implementation requires...that the staff within the $\mathrm{M} \& \mathrm{E}$ unit have the necessary $\mathrm{M} \& \mathrm{E}$ technical know-how and experience (Odhiambo, 2013). Acevedo, Rivera, Lima, \& Hwang, (2010) also agree with this view noting that both formal training and on the job experience are important in developing evaluators.

Experience in $M \& E$ can be acquired through continuous training, longer years of working in the same position, or working for different organizations. Odhiambo (2013) for instance, argues that M\&E capacity of employees should continuously be developed through training and other capacity building initiatives to ensure that they keep up with current and emerging trends in the field. Stetson (2011) also observes that even staff with extensive experience in $M \& E$ should be trained on the specific objectives, tools, and protocols for each M\&E activity to ensure that there is consistency and quality. Ngatia's (2015) study found that programme officers working in agribusiness NGOs in Murang'a County had received the necessary training in $M \& E$ either formally or through in-service training besides having several years of experience working with $M \& E$ systems. However, it is not clear how frequent the training in M\&E was carried out with no clear type of training established. IFRC (2011) notes that informal training (in M\&E) may include on-the-job guidance and feedback, such as mentorship in completing checklists, commenting on a report or guidance on how to use data management tools. Further, Stetson (2011) adds that M\&E training should cover the following key areas: objectives and overview of the project $\mathrm{M} \& \mathrm{E}$ system; principles of data collection, including key ethical considerations; and finally detailed focus on specific M\&E system topics such as datagathering forms, instruction sheets, and report formats. Therefore, care should be taken to ensure that M\&E training is prioritized to ensure projects are implement effectively because in most poorly performing projects training for monitoring and evaluation is not prioritized (Pearce \& Robinson, 2004).

The value of well thought-out and clearly defined institutional arrangements for monitoring, evaluation and learning (ME\&L) includes...clear job descriptions for line and field managers which ensured ME\&L are well integrated into their normal work routines (Lai, Hancock, \& Muller-Praefcke, 2012). However, weakness in the M\&E system is likely to result because job descriptions of staff involved in managing and implementing projects lack assigned M\&E responsibilities (Stetson, 2011). Kacapor-Dzihic's 2011 report on M\&E in Bosnia and Herzegovina NGOs for instance, noted that $\mathrm{M} \& \mathrm{E}$ teams did not have clarified $\mathrm{M} \& \mathrm{E}$ roles and relevant skills. As a consequence, $M \& E$ was done on ad-hoc basis by manager of organizations...with no day-to-day technical support and coverage for ongoing $M \& E$ needs and tasks (Kacapor-Dzihic, 2011). 
However it is not clear whether project performance was influenced in such NGOs. Among public organizations, Mbiti \& Kiruja, (2015) had similar findings oberving that staff entrusted with $M \& E$ had no technical skills, had no dedication to the function, and roles and responsibilities of monitoring and evaluation personnel had not been specified at the start of the projects. This revelation of inadequate $M \& E$ skills shows the weakness in the entire are of $\mathrm{M} \& \mathrm{E}$ in public benefit organizations.

\section{Nature of M\&E Information Systems and Performance of Non- Governmental Based Projects}

Communication in projects/programs is critical as it improves clarity on expectations, roles and responsibilities, as well as information on progress and performance (UNDP, 2009). This can be achieved by having an information system that provides timely, up to date, and accurate information to M\&E for decision making. An information system (IS) is an organized combination of people, hardware, software, networks and data resources that collects, stores, transforms and disseminates information in an organization (Kyalo, Mulwa, \& Nyonje, 2012) that supports organization's activities. In health programs, WHO (2008) documents that in its capacity, the health information system (HIS) ensures overall (data) quality, relevance and timeliness, and converts data into information for health-related decisionmaking. However, as observed by Buckingham et al (2008) cited by (Nielsen, 2012) information system is not only confined to computer hardware and software but a human activity (social) system which may or may not involve the use of computer systems'.

Project/program performance relies heavily on effective MIS in M\&E. Studies done in both government and NGOs have shown a strong relationship between MIS and performance of projects. Kahura (2013) in her study on the role of MIS in construction projects in Nairobi, Kenya, established a strong and positve correlation (0.954) between Project MIS and project success. Ngatia (2015) established a lower positive correlation (0.035) between using information systems in project activities and performance with a regression analysis showing that for every unit increase in Information systems use, a 0.024 increase in performance, which if not for the presence of extreneous variables, the relationship would be stronger. The positve relationship underscores the critical role MIS plays in ensuring reliable M\&E data. However, the importance of MIS to an organization has not been fully articulated in the studies. Pathfinder International (2016) explains that managers' effectiveness is largely dependent on the existence of an equally effective MIS which allows them to plan, monitor, and evaluate operations and performance by use of information collected. 
Strengthening the M\&E system in organizations by employing MIS relies heavily on technological advancements. It requires articulating an MIS concept, defining clear objectives and creating a vision to transform manual system into electronic (computerized) system focused on substantial improvement in the delivery of services (Khan, 2003). It is the reason various actors are looking to information and communication technology (ICT) to increase the efficiency, speed and accuracy of data collection, storage and analysis (INTRAC, 2013). Lai, Hancock, \& Muller-Praefcke (2012) observed that NGO projects in South East Asia demonstrated the feasibility and utility of ICT technology by establishing MIS with capabilities for web-based data capture and communication across multiple project sites and levels; and enhanced functionality from integration with GIS and remote-sensing tools and applications. Even though the MIS systems is able to deliver decision making information such as implementation status and progress (Lai, Hancock, \& Muller-Praefcke (2012), many NGOs operating with small fixed budgetsfind it hard to embrace advanced M\&E technologies, and acquire expertise due to high costs involved.Lai, Hancock, \& Muller-Praefcke (2012) notes that lack of modern telecommunication infrastructure and/or limited access to competent technical advice and support services could restrict the use of ICT in MIS establishment in certain project contexts.

M\&E Staff should understand information captured by the MIS, and its relevance to the activities and objectives of a particular programme/project. An effective manager works with his or her staff to ensure that each staff understands why certain data are being collected; how these data should be analyzed to support operations; when analyses should trigger other actions; and who should regularly receive and review data and analyses (Pathfinder International, 2016). The MIS should be understood by staff, at all levels, simple with fewer data elements, variables, formats, and procedures as much as possible, in addition to ability to create user-friendly presentations of data to share information with others. This view is supported by Kahura (2013) who while studying MIS in construction projects in Nairobi, Kenya, cautions against establishment of MIS that are too complicated and which may miss out on important information. In any case, are M\&E staff trained on the MIS so as to understand its operation? How important is it to have simple and user friendly MIS? Kahura (2013) argues that it is not the complexity of the software that matters but the quality of the information generated by the system and the ability of the user to use the information to manage the project. Although a study by Phiri (2015) on ISs in NGOs (AVU) found out that database for the MNP was rather complicated, build in Microsoft Access, and required services of a 
consultant, measures were put in place to ensure that databases were userfriendly and were updated regularly until the end of the projects.

MIS supports management in making timely and effective decisions for planning, monitoring, and managing the project (Rajalahti, Woelcke, \& Pehu, 2005) ensuring the quality of a project. A decision support system (DSS), a component of MIS; a computer based system (an application program) analyzes organizational (or business) data and then presents it in a way that helps the user to make business decisions more efficiently and effectively (Nowduri, 2012). In his study on the use of ISs in NGO projects (MNP and VUCCnet) in Kenya, Phiri (2015) recognized its application in data capturing in various beneficiary institutions, data cleaning, data entry, data analysis and report writing. In addition to understanding project expectations, databases were also used to retrieve information about projects and to generate trends of project progress from which new strategies were devised to improve project performance (Phiri, 2015). These findings are in agreement with Kahura's (2013) findings which showed that use of (MIS) software to generate quality information needed by the user (project manager) helped them perform their tasks in a more professional manner thus increasing the success rate of the construction projects. With adoption of computerised MIS, efficiency in delivery of interventions is enhanced due to timely availability of information. For instance, adopting digital data gathering (DDG) handheld devices such as smartphones and data pens greatly improves data collection, analysis, and, providing instantaneous data access, centralized information management, improved decision making, and better designed interventions (INTRAC, 2013).

\section{Stakeholder Participation in $\mathrm{M} \& \mathrm{E}$ and Performance of Non- Governmental Based Projects}

Growing emphasis on participatory approaches towards development, there has been recognition that monitoring and evaluation (M\&E) should also be participatory (World Bank,2016), for the purposes of enriching the quality of information. Garbutt (2013) argues that it is of no use having a complex $\mathrm{M} \& \mathrm{E}$ system if your partners are unable to collect data that provides the information you need. Participationis a process through which stakeholders at various levels engage in activities, such as monitoring or evaluation, of a particular project, program or policy, share control over the content, the process and the results of the (M\&E) activity and engage in taking or identifying corrective actions.

Participatory monitoring and evaluation (PM\&E) allows stakeholders at various levels to engage in monitoring or evaluating a particular project, program or policy; share control over the content, the process and the results of the $\mathrm{M} \& \mathrm{E}$ activity; engage in taking or identifying corrective actions 
(Sirker, WorldBank, \& Ezemenari, 2010). How important is stakeholder involvement in M\&E? Simister, (2009) argues that involving stakeholder in $M \& E$ generate better $M \& E$ data and analysis and also ensures service users have the right to be involved in all areas of work that have an influence over their lives. This increases the chances of a project/programme succeeding as high levels of engagement of users, clients and stakeholders in programmes and projects are critical to success (UNDP, 2009).

Measures need be taken to ensure that stakeholders are satisfied with their role in M\&E activities. This is because failure to involve stakeholders may generate opposition to any project activities. Were (2014) observes that misunderstanding, resentment, and outright sabotage of development projects can occur where development projects define resource use but exclude local people in decision making processes.

Meaningful engagement of various stakeholders in M\&E generates sufficient and relevant information that enhances project delivery. As UNFPA (2001) points out, involvement of various stakeholders such as programme stakeholders, central level decision makers, local level implementers, and communities, in programme design, implementation, monitoring and evaluation, improves programme quality and helps address local development needs. WHO (2006) also concurs with this view noting that in order to ensure effective M\&E for Maternal and Newborn Health $(\mathrm{MNH})$, partnerships should be established with different stakeholders, including the communities as well as other non-health sectors. Involvement of women and youth for instance has been argued to be beneficial by certain scholars. This view is confirmed by Agutu's (2014) findings on stakeholder involvement in School Feeding Programme by service providers in Kenya which revealed substantive involvement of school administrators, students, parents and community in $\mathrm{M} \& \mathrm{E}$. The resulting benefits were faster decision making, feedback, ownership, sustainability hence influence implementation of M\&E (Agutu, 2014). Involvement of other marginalized groups such as women and youth has also been recognized as vital for the success of projects. Srinivas (2015) points out that participation of women in all decision making processes-whether micro or macro-will ensure that broader goals are achieved, and will benefit all sections of the society. DFID(2010) also agrees that young people are the foundations for effective development, and if engaged they will improve many of the structural development challenges, including: enhancing the cohesion of families and communities, reducing health risks and advancing livelihood opportunities. However, studies still show that involvement of women in critical decision making positions is still limited in both government and NGOs. Were (2014) in her study of Lake Basin NGOs observed relative lower number of women in committee posisitons that managed NGO water projects in the region, further 
noting that the, involvement, did not necessarily translate into active participation in decision-making (Were, 2014).

Certain circumstances also limit the level of involvement stakeholders in project M\&E. In developing more extractive tools or methodologies for data collection and analysis in $\mathrm{M} \& \mathrm{E}$, project managers might involve service users as the passive providers of information during monitoring, review or evaluation processes, without having much say over how M\&E is carried out (Simister, 2009). In addition, complex organizations have to decide how far they are willing to allow local decision-making in these areas, and how far any tools, procedures or practices should be standardized (Simister, 2009). In evaluations for example, circumstances that require independent outside judgment and specialized information from which only technical experts can provide, a conventional approach to evaluation may be more suitable (UNFPA, 2001). Were (2013) also noted that although NGOs favored participatory projects where people from the community were actively involved, the degree to which M\&E activities involved the local community appeared limited. Analyzing M\&E approaches of three NGOs (Well NGO, Tank and Latrine NGO, and International NGO), Were's results showed that collection of information used in M\&E did not involve direct project participants.

Some scholars also contend that increasing community participation does not necessarily lead to improvement in project outcome. Community participation in projects can lead to start-up delays and cooptation by certain groups in the community (Were, 2014). According to Cleaver (1999) community participation is difficult to implement effectively because projects are clearly articulated sets of activities with little room for empowering people, one of the essential objectives of participation. However, community participation in $M \& E$ cannot be attained due to factors perceived to compromise the quality of $\mathrm{M} \& \mathrm{E}$ data. According to UNFPA(2001), community participation can be constrained by lack of literacy skills, insufficient time, the intensity of analytical work to be undertaken during the evaluation, and the fact that many of the issues covered during the evaluation are not directly relevant to community members.A study by (Mugo \& Oleche, 2015) on M\&E in government developpment projects indicated that stakeholders' participation in implementation of $\mathrm{M} \& \mathrm{E}$ had a negative effect in the short run. Many scholars have, however, not focussed on the extent to which engagement should be accepted and to what to level should it be permitted during project implementation. In managing stakeholders engagement, both from stakeholders' analysis, selection and involvement, it is important to understand when each stakeholder(s) input will be needed. For instance, UNFPA (2001) explains that participatory evaluations are particularly useful 
when there are questions about implementation difficulties or programme effects on different stakeholders or when information is wanted on stakeholders' knowledge of programme goals or their view of progress. Or else as observed by (Mugo \& Oleche, 2015), too much stakeholders' involvement could lead to undue influence on $\mathrm{M} \& \mathrm{E}$ functions thus reducing the likelihood of M\&E system implementation.

\section{Research methodology \\ Research Design}

This study adopted a mixed method appraoch incorporating descriptive survey research designand correlational designs. A descriptive research design in this study was key in describing the the nature of the M\&E systems and factors influencing their performance. The design also assisted in testing the level of significance between M\&E factors and performance of maternal health projects in NGOs. The study also incorporated a correlational research design in oder to determine the relationship between $M \& E$ factors-M\&E plans, human resource capacity, information system and stakeholder participation (independent variables) and performance of MHPs in NGOs (dependent variable).

\section{Target Population}

This study targeted programme and project managers, M\&E officers, project field officers, volunteers, and interns involved in M\&E activities in four NGOs implementing MHPs in Bungoma South Sub-County. A total of 101 respondents from the participating NGOs were targeted.

\section{Sample Size and Sampling Procedure}

Owing to the small size number of the target population, a census was conducted on all the staff of NGOs involved in MHPs in Bungoma South Sub-County. Mugenda \& Mugenda (2003) recommends that if the target population is small, then taking the whole population in such cases is advisable. In this case, all staff with M\&E roles, that is, programme/project managers, M\&E officers, field staff, volunteers and interns, were included in the final study sample. Appointments with each staff in their respective NGOs were scheduled and questionnaires were then administered.

Data was collected through questionnaires which allowed for analysis using SPSS software. 


\section{Data analysis, presentation, interpretation and discussions Introduction}

Data from three NGOs, ACE Africa (AA), Save The Children (STC) and CREADIS implementing MHPs was secured and used in analysis. The views and opinions of respondents are discussed below.

\section{Influence of $M \& E$ work plans on performance of non-governmental based maternal health projects in Bungoma South Sub-County}

The findings of the study show the three NGOs (AA, STC, and CREADIS) had M\&E plans in place. Although few of the respondents (33.3\%) claimed that they had been involved in the development of M\&E plans in their organization, majority of respondents $(86.4 \%)$ from all the three NGOs acknowledged that their organizations had shared the M\&E plans with their staff. Simister (2015) recommends that, as a best practice, a wide engagement with different stakeholders as possible, and certainly anyone expected to carry out the work contained in the M\&E plan should be informed or consulted during M\&E plan's development. However, it is not enough to share the $M \& E$ plan to the staff and other stakeholders involved in M\&E. Staff should be trained on the various components of the M\&E of the M\&E plans. $38.3 \%$ of respondents were well trained, $53.1 \%$ had little training while $8.6 \%$ had not been trained. The large number of respondents (83.9\%) who needed training on the M\&E plan is indicative of little understanding of the components of the M\&E plans by staff in the three NGOs (AA, STC, and CREADIS). It is also the reason $46.9 \%$ of the respondents indicated that that their M\&E activities didn't match their project activities. With little guidance of project activities by the M\&E plans in the three NGOs, project success cannot be measured accurately without proper conception of the M\&E plans, and thus the stage is set for achievement of little project success. If you can't measure how well you are doing against targets and indicators, you may go on using resources, without changing the circumstances you have recognized as a problem at all (Karani, Bichanga, \& Kamau, 2014).

The scope of M\&E plans should be articulated clearly to all staff implementing the MHPs. However nearly half of the respondents were privy to the narrower scope of $\mathrm{M} \& \mathrm{E}$, where all $\mathrm{M} \& \mathrm{E}$ efforts are geared towards achieving of project activities, outputs and outcomes. These findings agree with Phiri, (2015) that with narrower scope M\&E plan, consideration is given to achievement of project outputs, outcomes and goals where the M\&E plan's role was to guide the tracking of achievement of results. However this is a limited role of M\&E plan meaning that staff have little chance of learning from the projects they implement, in terms of project achievements and failures. As Simister (2015) observes, an M\&E plan should encompass 
issues involving the analysis and use of information, reporting schedules, learning mechanisms, training, knowledge management and resources in addition to the indicator matrix. An effort to incorporate these aspects to the M\&E plans and share them with the implementing staff is underway considering $51.9 \%$ of the respondents acknowledged their inclusion.

It is important that the M\&E plan is regularly updated to keep it relevant throughout the project cycle. The findings indicate that majority $(72.8 \%)$ were aware that the M\&E plan in their organization is updated. The reasons given for updating the $M \& E$ plans were; review and set new targets, improve $M \& E$ activities and project implementation, learn from success and achievements. These results confirm Simister (2015) view that changes might need to be made because $M \& E$ systems or processes are not working properly, or because the project or programme itself has changed, and the M\&E approach needs to be altered as a result. However, apart from CREADIS, responses from AA and STC varied as to when exactly are the M\&E plans updated. This shows that staff working in the projects might miss out any changes that may be made on the M\&E plans.

\section{Influence of Human Resource Capacity on Performance of Non- Governmental Based Maternal Health Projects in Bungoma South Sub- County, Kenya.}

Anyone involved in implementation of maternal health projects should be competent enough to carry out the roles assigned to him/her. The findings of the study reveal that respondents inthe three NGOs (AA, STC, and CREADIS) had a qualified staff with majority (96.3\%) having university degrees and middle level college qualifications, while a few (34.6\%) having special training in M\&E. In addition, it was established that the three NGOs hold internal trainings on M\&E to equip their staff with skills to effectively carry out their M\&E roles. Stetson (2011) points out that even staff with extensive experience in M\&E should be trained on the specific objectives, tools, and protocols for each $\mathrm{M} \& \mathrm{E}$ activity to ensure that there is consistency and quality. The findings however, indicate that $\mathrm{M} \& \mathrm{E}$ training in the three NGOs was inadequate averaging only 2 trainings per reporting period. Further, emphasis of the M\&E training was mainly on data presentation, dissemination and reporting, data collection tools, and stakeholder partnerships, while other equally important areas such as data quality, data storage, analysis and use, and log frames and work plans received little attention. The findings confirm Wanjiku (2015) findings about construction projects in Nyandarua County which observed inadequate training and M\&E expertise in areas such as design skills particularly Log Frame design, indicator setting, design of data collection instruments, with non-existent with data collection skills. Therefore to build a sustainable M\&E system, 
(Acevedo, Rivera, Lima, \& Hwang, 2010) points out that adequate supply of competent human resource capacity is critical.

Majority of respondents $(62.9 \%)$ were either not sure or disagreed that their project activities matched their activities in their job descriptions in the three NGOs (AA, STC, and CREADIS). This means that M\&E staff working in these NGOs are not clear about their M\&E roles, and which are not captured in their job descriptions. This situation in maternal health NGOs in Bungoma South Sub-County mirrors that of $\mathrm{M} \& \mathrm{E}$ in Bosnia and Herzegovina NGOs where M\&E teams reported not to have clarified M\&E roles and relevant skills, (Kacapor-Dzihic,2011). This is a weakness in the M\&E system that, according Stetson, (2011), is likely to result because job descriptions of staff involved in managing and implementing projects lack assigned M\&E responsibilities.

Staff in working in the MHPs had a fairly sufficient experience to effectively implement the projects and conduct their M\&E activities. The findings show that respondents had a working experience in $M \& E$ averaging of 4.396 years, having worked in average of 2 organizations. Therefore, in terms of experience, the respondents were in a good position to effectively implement their assigned M\&E roles. These findings agree with (Acevedo, Rivera, Lima, \& Hwang, 2010) who observe that both formal training and on the job experience are important in developing evaluators.

\section{Influence of Nature of M\&E Information Systems Adopted on Performance of Non-Governmental Based Maternal Health Projects}

Technological advancements adopted in M\&E information system is key in strengthening the M\&E system. As pointed out by Khan (2003), it requires articulating an MIS concept to transform manual system into electronic (computerized) system focused on substantial improvement in the delivery of services. However, the findings indicate that the three NGOs (AA, STC, and CREADIS) are yet to fully embrace technology in their MIS. In data collection, the NGOs especialy AA and CREADIS largely use hard paper questionnaires with only STC using both hard paper questionniares and tablets/smartphones. This means that a lot of time is consumed in data collection, data entry and verification, and data analysis before the information can be availed to decion makers. In data analysis all the three NGOs use the basic data analysis software, MS excel, while advanced softwares such as SPSS and STATA which provide more accurate data analysis, better organization of data outputs and large number of options in data presentations were rarely mentioned. In data storage, only STC has secure servers within their organizations to store data, while in AA and CREADIS project data is still stored in paper files and cabinets, and office or personal computers. This is in contrast to Phiri's (2015) findings which 
established that databases were also used to retrieve information about projects and to generate trends of project progress. This expose project data to destruction or manipulation that may happen to them. However when it comes to data diseemination, all the three NGOs have embraced use of emails and other convenient methods such as dashboards. This methods avails project information to decision makers faster and on timely basis.

Although the speed in which the MIS employed in the three NGOs was quite faster according to majority of respondents, there is room for improvement to make it more efficient, faster and user friendly. Slightly more than half of respondents $(50.6 \%)$ indicated that their MIS takes time to understand and use. This means that users had a difficult time using it. These results are in agreement with Phiri (2015) on ISs of Africa Virtual University (AVU) which found out that database for the MNP was rather complicated, build in Microsoft Access, and required services of a consultant Phiri's (2015) findings which showed that database for the MNP was rather complicated, build in Microsoft Access, and required services of a consultant. Wherever any part of the IS is viewed as complex by the user, the more time it takes to operate which results to delay in decision making which relies on the information received. Kahura (2013) points out that it is not the complexity of the software that matters but the quality of the information generated by the system and the ability of the user to use the information to manage the project. Investing more in simple, relevant and current technologies in MIS such as DDG handheld devices such as smartphones and data pens can greatly improves data collection, analysis, and, providing instantaneous data access, centralized information management, improved decision making, and better designed interventions (INTRAC, 2013). In additon, training of staff on the MIS tools and methods is also important to increase the understanding of MIS and speed in which M\&E activities are carried out.

\section{Influence of stakeholder participation on performance of non- governmental based maternal health projects in Bungoma Kenya.}

Involving stakeholder in $M \& E$ generate better $M \& E$ data and analysis, and also ensures service users have the right to be involved in all areas of work that have an influence over their lives (Simister,2009). The findings of the study indeed confirmed that stakeholders were involved in M\&E activities of the three NGOs (AA, STC, and CREADIS). In addition, involvement of women in all decision making processes-whether micro or macro-will ensure that broader goals are achieved, and will benefit all sections of the society (Srinivas,2015). However, the findings indicate that involvement women and youth in $\mathrm{M} \& \mathrm{E}$ activities was not as equally done as much as men. This shows that underlying cultural issues that sideline women 
and youth in issues that affect them still apply in the maternal health projects in the three NGOs. These findings are in agreement with Were's (2014) findings which noted lower number of women in committee posisitons that managed NGO water projects in the region (lake Victoria Basin), and where their involvement did not necessarily translate into active participation in decision-making.

Stakeholder involvement was highly pronounced in less technical areas such as data collection and providing information. From the findings, technical M\&E areas such as data analysis, data dissemination and M\&E decision making received little responses (16.0\%) as areas of stakeholder involvement because of the perceived lack of technical expertise among project stakeholders to conduct such activities. M\&E officers in the three NGOs were reluctant in involving stakeholders in M\&E data collection because they believe it might compromise the quality of $M \& E$ data. This view is in agreement with Simister's (2009) who believes that in developing more extractive tools or methodologies for data collection and analysis, service users can be used as passive providers of information during monitoring, review or evaluation processes.

Community participation can be constrained by lack of literacy skills, insufficient time, the intensity of analytical work to be undertaken during the evaluation (UNFPA, 2001). The findings show that involvement of project stakeholders slowed down implementation of $\mathrm{M} \& \mathrm{E}$ activities as opined by $58.7 \%$ of the respondents. This is because a lot of time is taken before decisions are agreed upon by different stakeholders. In addition, with the perceived inadequate qualifications among primary stakeholders, a lot of time will be needed in understanding various tools and methods employed in M\&E activities and this is likely to consume project timelines. These findings agree with (Mugo \& Oleche, 2015), who concluded that too much stakeholders' involvement could lead to undue influence on M\&E functions thus reducing the likelihood of M\&E system implementation. Were (2014) also points out that community participation in projects can lead to start-up delays and cooptation by certain groups in the community. However, the findings show that there was need to involve project stakeholder more in M\&E meaning the three NGOs could benefit from rich and quality data with stakeholders input.

\section{Correlational Analysis}

The section presents a correlational analysis between aspects of M\&E systems: M\&E plans, Human resource capacity, information system adopted, stakeholder involvement in M\&E, and performance of Maternal Health Project in terms of project timeliness, project effectiveness, project 
timeliness, and number of deliverables respectively. The results are summarized in table 1 .

Table 1: Correlation Analysis.

\begin{tabular}{|c|c|c|c|c|c|}
\hline & $\begin{array}{c}\text { Performance of } \\
\text { MHPs }\end{array}$ & M\&E Plans & $\begin{array}{c}\text { Human } \\
\text { resource } \\
\text { Capacity }\end{array}$ & $\begin{array}{c}\text { Information } \\
\text { Systems }\end{array}$ & $\begin{array}{c}\text { Stakeholder } \\
\text { participation }\end{array}$ \\
\hline $\begin{array}{c}\text { Performance of } \\
\text { MHPs }\end{array}$ & 1.000 & $0.605 * * *$ & $0.530^{* * *}$ & $0.533 * * *$ & -0.489 \\
\hline M\&E Plans & $0.605 * * *$ & 1.000 & & & \\
\hline $\begin{array}{c}\text { Human resource } \\
\text { Capacity }\end{array}$ & $0.530^{* * *}$ & & 1.000 & & \\
\hline $\begin{array}{c}\text { Information } \\
\text { Systems }\end{array}$ & $0.533 * * *$ & & & 1.000 & 1.000 \\
\hline $\begin{array}{c}\text { Stakeholder } \\
\text { participation }\end{array}$ & -0.489 & & & & \\
\hline
\end{tabular}

**. Correlation is significant at the 0.01 level (2-tailed).

From the table 1, a strong positive coefficient correlation of 0.607 was established between knowledge of M\&E plans and project performance in terms of project timeliness. The correlation was significant at 0.01 level of significance. A positive strong correlation indicates that $\mathrm{M} \& \mathrm{E}$ plans influences performance of MHPs in the three NGOs (AA, STC, and CREADIS). This means that an increase in knowledge of M\&E plans would be expected to be completed within their planned timeframes. These findings are in agreement with Phiri's findings which established a strong correlation coefficient of 0.745 and 0.783 of AVU and VUCCnet project performance respectively and M\&E plans.(SFCG, 2010) also points out that the M\&E Plan provides the steps you can use to document project activities, answer evaluation questions, and show progress toward project goals and objectives.Further a relatively strong positive correlation coefficient of 0.530 was established between human resource capacity and performance of MHPs in terms of project effectiveness at 0.01 level of significance (two tailed). This shows that human resource capacity in M\&E is very key in the effective implementation of projects and for the project to achieve the desired results. This means an increase in skills and capacities in staff implementing MHPs project would equally translate to effective delivery of the projects leading to achievement of its goals. These findings agree with, Ngatia's (2015) results which found a positive correlation between human resources use in monitoring and evaluation and performance of agribusiness projects.Additionally, a relatively strong positive correlation of coefficient of 0.533 was established between information system adopted and performance of MHPs in terms of project timeliness. This implies that monitoring and evaluation information is a very key factor in performance of projects in terms of its timeliness. The relation was significant at 0.01 level of 
significance. Therefore, enhancing ISs in M\&E with modern technologies and training would increase the speed with which data is availed to decision makers. This implies that MHPs remains on track as planned. These findings agree with Kahura (2013) and Phiri's study findings which established positive relationships of 0.954 and 0.035 respectively between Project MIS and project performance. Finally, a moderately negative correlation coefficient of -0.489 was established indicating existence of a significant negative relationship at 0.01 level of significance. This shows that stakeholder participation negatively influences performance of projects in terms of achievement of major project milestones/deliverables. This shows that increasing stakeholder involvement would hinder achievement of project goals in terms of achieving major milestones. These results confirm Mugo \& Oleche (2015) views that stakeholders' participation in implementation of M\&E has a negative effect in the short run, and that too much stakeholders' involvement could lead to undue influence on $\mathrm{M} \& \mathrm{E}$ functions thus reducing the likelihood of M\&E system implementation.

\section{Regression Analysis}

The section presents multiple regression with independent variables: knowledge of M\&E plans, human resource capacity, MIS adopted and stakeholder participation and dependent variable: project performance based on project timeliness. A regression equation of $(\mathrm{Y}=\beta 0+\beta 1 \mathrm{X} 1+\beta 2 \mathrm{X} 2+$ $\beta 3 \mathrm{X} 3+\beta 4 \mathrm{X} 4+\varepsilon)$ was used. The results were summarized as shown in table 2 .

Table 2. Showing multiple regression analysis between variables in M\&E system and performance of maternal health projects based on Number of deliverables

Coefficients $^{\mathrm{a}}$

\begin{tabular}{|c|c|c|c|c|c|c|}
\hline \multirow{2}{*}{\multicolumn{2}{|c|}{ Model }} & \multicolumn{2}{|c|}{$\begin{array}{l}\text { Unstandardized } \\
\text { Coefficients } \\
\end{array}$} & $\begin{array}{r}\text { Standardized } \\
\text { Coefficients } \\
\end{array}$ & \multirow[t]{2}{*}{$\mathrm{T}$} & \multirow[t]{2}{*}{ Sig. } \\
\hline & & B & Std. Error & Beta & & \\
\hline \multirow{5}{*}{1} & (Constant) & 4.087 & .351 & & 11.641 & .000 \\
\hline & $\begin{array}{l}\text { knowledge of M\&E } \\
\text { plans }\end{array}$ & .073 & .220 & .034 & .330 & .074 \\
\hline & $\begin{array}{c}\text { experience and skills in } \\
M \& E\end{array}$ & .225 & .142 & .176 & 1.590 & .016 \\
\hline & MIS adopted & .282 & .094 & .330 & 2.988 & .004 \\
\hline & stakeholder participation & -.297 & .105 & -.297 & -2.833 & .006 \\
\hline
\end{tabular}

a. Dependent Variable: performance based on number of project deliverables

From table 4.44 above, the relationship of variables was illustrated in the following equation:

$$
\mathrm{Y}=4.087+0.073 \mathrm{X} 1+0.225 \mathrm{X} 2+-0.282 \mathrm{X} 3+0.297 \mathrm{X} 4
$$


The regression equation indicates that, taking all the variables at a constant zero, performance of maternal health projects will be at 4.087 . The equation also indicates that taking all independent variable constant at zero, a unit increase in knowledge of $\mathrm{M} \& \mathrm{E}$ work plans would lead to a 0.073 increase in performance of MHPs in terms number of deliverables. Further holding all other independent variables at a constant zero, a unit increase in human resource capacity would lead to a 0.225 increase in performance of maternal health projects in terms number of deliverables. Holding all other independent variables at a constant zero, a unit increase in MIS would lead to a 0.282 increase in performance of maternal health projects in terms number of deliverables. Finally, holding all other independent variables at a constant zero, a unit increase in stakeholder participation would lead to a -0.297 increase in performance of maternal health projects in terms number of deliverables. Therefore, all the variables had a significant influence of on performance of maternal health projects in NGOs Bungoma county with M\&E plans having the least influence.

\section{Conclusion}

M\&E systems in the three NGOs (AA, STC, and CEADIS) has an influence on performance of MHPs. This was shown by a performance of 4.087 when all other independent variables are at a constant zero. Aspects of M\&E such M\&E plans, human resource capcaity in $M \& E, M \& E$ information system and stakeholder particaption in $M \& E$ were shown to infuence performance of MHPs. A strong relationship (0.607) was established between M\&E plans and performance of MHPs in terms of project timeliness. It was establsihed that a unit increase in knowledge of M\&E work plans would lead to a 0.073 increase in performance of MHPs when all other independent variables at a constant zero. It means therfore that this relationship could be improved more emphasis being place staff training on M\&E plans.

Further, staff human resource capacity in $\mathrm{M} \& \mathrm{E}$ influences performance of MHPs. This was shown by a fairly strong coefficient correlation of 0.530 established between human resource capacity and performance of MHPs. A unit increase in human resource capacity would lead to a 0.225 increase in performance of MHPs in terms number of deliverables when other independent variables are held constant.

In addition, MIS adopted for M\&E has an influence on performance of MHPs. With a strong correlation coefficient of 0.533 , a unit increase in MIS would lead to a 0.282 increase in performance of MHPs in terms project deliverables when all the independent variables are at a constant zero. It follows therefore that performance of MHPs can be improved if the organizations can invest in modern technology in their M\&E activities. 
Finally, stakeholder involvement in M\&E of MHPs had some negative influence on their performance (-0.489). A unit increase in stakeholder participation would lead to a -0.297 increase in performance of MHPs in terms number of deliverables when all other independent variables are held at a constant zero. This means that too much stakeholder involvement in M\&E would slow down performance of MHPs in the NGOs (AA, STC, and CREADIS). Therefore, stakeholder involvement should be carefully managed so as to enrich quality of $\mathrm{M} \& \mathrm{E}$ data and also ensure that project delivery is not slowed down.

As a conclusion, it can be said that the project management methodology or processes should be applied to achieve better results of the projects undertaken by the maternal health NGOs in Bungoma South SubCounty. The project management methodology allows for a project to be broken down to five process groups: initiation process, planning process, executing process, monitoring and control process and closure process. This methodology places importance on the monitoring and control process and requires the monitoring and control process to interact with other processes. According to Project Management Institute(2008), the key benefit of this process group is that project performance is observed and measured regularly and consistently to identify variances from the project management plan.

\section{Recommendations for Policy and Practice}

Based on the findings, it was recommended that programme/project managers of the MHPs in the three NGOs (AA, STC, and CREADIS) engage the Bungoma County technical working group in health to train their staff on M\&E plans and harmonize their activities and job descritpions to match their $M \& E$ plans. Further, training on $M \& E$ roles and activities is increased from the current average of 2 trainings per reporting period to at least twice a month. Further the training touch on neglected areas such as data quality, data storage, analysis and use, and log frames and work plans, and attitude change towards M\&E training. Further, the three should NGOs undertake a routine data quality assurance (RDQA) in order to detect M\&E areas that staff in their organizations have difficulties in and recommend relevant training in the areas. Investment in ICT in MIS amongst the three NGOs (AA, STC and CREADIS) such as DDG devices, advanced data analysis softawares (such as SPSS and STATA) and web-based servers (cloud) that will ensure accuracy, timeliness and security project data and information. To enrich the effectiveness of MHP activities using quality M\&E data and information, the study recommends involvement of primary beneficiaries in key M\&E areas such as data collection, M\&E data dissemination, and decion making. This should be carefully be done, at least annually, so that their involvement does not delay project execution. 


\section{References:}

1. AHMED, Z. U. (2004). ACCOUNTABILITY AND CONTROL IN NON-GOVERNMENTAL - A CASE OF BANGLADESH. Fourth Asia Pacific Interdisciplinary Research in Accounting Conference (pp. 1-25). Manchester : UNIVERSITY OF MANCHESTER.

2. Carman, J. G. (2007). Evaluation Practice Among Community-Based Organizations. American Journal of Evaluation, 66-75.

3. Davies, R. (2001, April 12). Monitoring and Evaluating NGO Achievements. Retrieved from Monitoring and Evaluation NEWS: http://www.mande.co.uk/docs/arnold.htm

4. Emmanuel, Z. N. (2015, May 11). The State of Monitoring and Evaluation of NGOs' Projects in Africa. Retrieved from https://www.linkedin.com/pulse/state-monitoring-evaluation-ngosprojects-africa-yannick-emmanuel

5. Githika, M. S. (2013). Influence of Project Management Practices on Implementation f HIV and AIDS Projects: A Case of Civil Society Organizations in Imenti North Subcounty, Meru County Kenya. Master's Thesis, 1-96.

6. IFRC. (2011). Project/programme monitoring and evaluation (M\&E) guide. Geneva.

7. Kacapor-Dzihic, Z. (2011). Monitoring and Evaluation Needs Assessment Report. Sarajevo: Technical Assistance for Civil Society Organisations.

8. Kahura, M. N. (2013). The Role of Project Management Information Systems towards the Success of a Project: The Case of Construction Projects in Nairobi Kenya . International Journal of Academic Research in Business and Social Sciences , 104-115.

9. Karani, F. N., Bichanga, W. O., \& Kamau, C. G. (2014). Effective use of monitoring and evaluation systems in managing HIV/AIDS related projects: A case study of local NGOS in Kenya. Science Journal of Business and Management, 67-75.

10. Khan, K. (2003, June). Strengthening of Monitoring and Evaluation System. Islamabad.

11. Kirsch, D. C. (2013). Accountability in Children's Development Organizations . PH.D Thesis, 1-50.

12. Lahey, R. (2015, November). Common issues affecting monitoring and evaluation of large ILO projects: Strategies to address them. $i$ eval THINK Piece(9).

13. Lai, K., Hancock, J., \& Muller-Praefcke, D. (2012). Stocktaking of $M \& E$ and Management Information Systems Selected agricultural and rural development projects in South Asia. Rome: FAO Investment Centre . 
14. Mbiti, V. M., \& Kiruja, D. E. (2015). Role of Monitoring and Evaluation on Performance of Public Organization Projects in Kenya:

A Case of Kenya Meat Commission. International Journal of Innovative Development \& Policy Studies.

15. Mugenda, O. M., \& Mugenda, A. G. (2003). RESEARCH METHODS: Quantitative and Qualitative Approaches. Nairobi: Acts Press.

16. Mugo, P. M., \& Oleche, D. M. (2015). Monitoring and Evaluation of Development Projects and Economic Growth in Kenya . International Journal of Novel Research in Humanity and Social Sciences, 59-60.

17. Muzinda, M. (2007). Monitoring and Evaluation Practices and Challenges of Gaborone Based Local NGOs Implementing HIV/AIDS Projects in Botswana . Dissertation, 12-142.

18. Ngatia, N. P. (2015). Influence of Monitoring and Evaluation Systems Use on Performance of Non-governmental Organizations: A Case of Agribusiness Projects in Murang'a County, Kenya. Master's Thesis.

19. Odhiambo, F. O. (2013, May 3). THE 12 COMPONENTS OF M\&E SYSTEMS. Retrieved from MONITORING AND EVALUATION BLOG: https://evaluateblog.wordpress.com/2013/05/03/the-12-keycomponents-of-me-systems/

20. Ooko, S. (2014). NGOs and development in Africa: Lessons for donors. Retrieved from Thompson Reuters Foundation News: http://news.trust.org//item/20140303151017-208vf/

21. Rajalahti, R., Woelcke, J., \& Pehu, E. (2005). Monitoring and Evaluation for World Bank Agricultural Research and Extension Projects: A Good Practice Note. Agricultural and Rural Development Discussion Paper 20.

22. Ramadan, M. A., \& Borgonovi, E. (2015). Performance Measurement and Management in Non-Governmental Organizations. IOSR Journal of Business and Management (IOSR-JBM), 70-76.

23. SFCG. (2010). Monitoring and Evaluation Plan Module. UKAID.

24. Simister, N. (2015). M\&E Plans. INTRAC Publications, 1-3.

25. Simister, N., \& Smith, R. (2009). Developing M\&E Systems for Complex Organisations: A Methodology. International NGO Training and Research Centre.

26. Stetson, V. (2011). Monitoring and Evaluation (M\&E) Guide. Baltimore. Retrieved from http://www.crsprogramquality.org.

27. SU, Y. (2010). The failure of the American ABC HIV prevention model in Botswana. Studies by Undergraduate Researchers at Guelph, 93-100. 
28. Taylor, L. (2001). Good Monitoring and Evaluation: Guidance notes. 29. UNFPA. (2001). TOOL NUMBER 4: Stakeholder Participation in Monitoring and Evaluation. The Programme Managers Monitoring and Evaluation Toolkit, 3-10.

30. UNFPA Kenya. (2014, August 13). Counties with the Highest Burden of Maternal Mortality . Retrieved from UNFPA Kenya: http://kenya.unfpa.org/news/counties-highest-burden-maternalmortality

31. Wanjiku, S. M. (2015). Monitoring and Evaluation Factors Influencing the Performance of Road Infrastructural Projects: A Case Study of Nyandarua County, Kenya.

32. Were, V. L. (2014). The Nexus of Nongovernmental Organization Water Projects, Monitoring and Evaluation, and Kenya's Water Law. Dissertation.

33. Wyld, A. (2012, April 18). Foreign aid cuts focus on accountability, Oda says. Retrieved from CBCNEWS: http://www.cbc.ca/news/politics/foreign-aid-cuts-focus-onaccountability-oda-says-1.1165687

\section{Appendix i: list of abbreviations}

$\begin{array}{ll}\text { AA } & \text { - Ace Africa (Kenya) } \\ \text { AIDS } & \text {-Acquired Immune Deficiency Syndrome } \\ \text { AVU } & \text {-Afrcian Virtual University. } \\ \text { CREADIS- Community Research in Environmental and Development Initiatives. } \\ \text { DDG } & \text {-Digital Data Gathering } \\ \text { DFID- } & \text {-Department for International Development. } \\ \text { IFRC } & \text {-International Federation of Red Cross and Red Crescent Societies } \\ \text { IS } & \text { - Information System } \\ \text { ICT } & \text {-Information and Communication Technology } \\ \text { HIV } & \text { - Human Immuno-Deficiency Virus } \\ \text { MIS } & \text { - M\&E Information Systems } \\ \text { MHPs } & \text { - Maternal Heath Projects } \\ \text { MNP } & \text { - Multinational Project } \\ \text { M\&E } & \text { - Monitoring and Evaluation } \\ \text { NGO } & \text {-Non-Governmental Organization } \\ \text { OECD } & \text { - Organization for Economic Co-operation and Development } \\ \text { SFCG } & \text { - Search For Common Ground } \\ \text { SPSS } & \text {-Statistical Package for Social Science } \\ \text { UNFPA } & \text { - United Nations Population Fund. } \\ \text { UNDP } & \text {-United Nations Development Programme. } \\ \text { USAID } & \text { - United States Agency for International Development. } \\ \text { VUCCnet } & \text { - Virtual University for Cancer Control Network } \\ \text { WHO } & \text { - World Health Organization. }\end{array}$

